\title{
Bermain Peran "Pelangi di Sekolahku” untuk Meningkatkan Pengetahuan Toleransi Anak Usia Prasekolah
}

Rusmaladewi \& Wisjnu Martani

PG.PAUD Universitas Palangka Raya JL. Tunjung Nyaho, Jl. Yos Sudarso, Palangkaraya 73112, Kalimantan Tengah \& Jl. Humaniora No. 1 Bulaksumur; Kota Yogyakarta 55281.

Zeromilo3111@gmail.com

\begin{abstract}
As an archipelago country, Indonesia has 1.128 tribes, therefore, Indonesia has a lot of cultures, languages, races, religions and customs. This diversity if it is not well managed, is able to be the source of conflict. As the effort of preventing the conflict, since the early age of children, it is better to give them knowledge of tolerance. The objective of this research is to carry out the validation of role playing module "Pelangi Di Sekolahku" towards the knowledge of tolerance on the early age of children particularly the kindergarten students. The participants of this research were 32 kindergarten children. The participants were separated into control group (18 children) and experiment group (14 children). The hyphotesis of this research was that the role playing module "Pelangi Di Sekolahku" was able to improve the knowledge of tolerance on the early age of children. The method of the research used untreated control group design with pretest and posttest. The result of the statistical test which used mixed anava showed that there was the significantly difference between experiment group and control group with sig $(0.000)<0.01$. The effective contribution of the role playing on the experiment group was $79.1 \%$.
\end{abstract}

Key words : Tolerance, Role playing, Preschool Children

\begin{abstract}
ABSTRAK
Sebagai negara kepulauan di Indonesia terdapat 1.128 suku bangsa, sehingga Indonesia memiliki bermacam-macam budaya, bahasa, ras, agama dan adat isitiadat. Keragaman ini apabila tidak dikelola dengan baik dapat berpotensi menjadi sumber konflik. Sebagai upaya mencegah munculnya konflik, sejak usia dini anak sebaiknya mulai diberi pengetahuan tentang toleransi. Penelitian ini bertujuan untuk melakukan validasi modul bermain peran "pelangi di sekolahku” terhadap pengetahuan toleransi pada anak usia dini khususnya siswa di TK. Subjek penelitian berjumlah 32 anak TK. Subjek dibagi menjadi kelompok kontrol (18 anak) dan kelompok eksperimen (14 anak). Hipotesis yang diajukan adalah modul bermain peran "Pelangi Di Sekolahku” dapat meningkatkan pengetahuan toleransi pada anak usia dini. Metode yang digunakan dalam penelitian ini adalah untreated control group design with pretest and posttest. Hasil uji statistik menggunakan anava campuran menunjukan adanya perbedaan yang signifikan antara kelompok eksperimen dan kelompok kontrol dengan $\operatorname{sig}(0,000)<0,01$. Sumbangan efektif bermain peran pada kelompok eksperimen sebesar $79,1 \%$.
\end{abstract}

Kata Kunci: Toleransi, Bermain peran, Anak Usia Prasekolah 


\section{PENDAHULUAN}

Indonesia sebagai negara kepulauan memiliki berbagai macam suku bangsa. Berdasarkan survei yang dilakukan oleh Badan Pusat Statistik (BPS) mengenai jumlah suku bangsa tersebut, Kepala BPS, Rusman Heriawan dalam rapat dengar pendapat (RDP) dengan Komisi XI DPR RI, menyampaikan bahwa dari hasil sensus penduduk terakhir, diketahui bahwa Indonesia terdiri dari 1.128 suku bangsa (JPPN, 2010). Kondisi tersebut menciptakan masyarakat yang multicutural, multiracial dan multilingual. Bangsa Indonesia menjadi kaya dengan keragaman budaya, ras, bahasa, agama dan adat istiadat. Keragaman ini apabila tidak dikelola dengan baik berpotensi menimbulkan konflik.

Konflik terjadi karena sifat dan karakter yang berbeda yang dimiliki oleh setiap individu ditambah dengan tujuan dan kepentingan yang berbeda pula, Ketidaksamaan itulah yang kemudian membuat individu merasa terancam dengan keberadaan individu lain (Soekanto, 1990). Walzer (dalam Wittenberg, 2001) menyebutkan bahwa dalam perbedaan harus ada toleransi. Toleransi sangat dibutuhkan dalam masyarakat yang memiliki karakteristik dan cara hidup berbeda (Oberdiek, dalam Bergen \& Collier, 2009). Keterbatasan pengetahuan dan kemampuan individu dalam memahami perbedaan, mengurangi prasangka dan diskriminasi, menjadi tujuan penting dalam penelitian baik secara teoritis maupun praktis (Aboud \& Doyle, 1996).

Untuk mencegah timbulnya konflik perlu dikembangkan karakter toleran. Karakter ini sebaiknya ditanamkan sejak kecil kepada lingkungan anak. Menyadari hal tersebut, pemerintah melalui Kementerian Pendidikan dan Kebudayaan menerapkan pendidikan karakter di seluruh jenjang pendidikan, termasuk di lembaga-lembaga Pendidikan Anak Usia Dini (PAUD).
Keberagaman dan keadilan merupakan hal yang menjadi pusat perhatian pada pendidikan anak usia dini (Vanderbrock, 2011). Toleransi memerlukan perhatian untuk dikembangkan agar menjadi budaya yang mengakar pada jiwa anak sejak dini. Sujino (2009) mengatakan bahwa usia 0-6 tahun merupakan usia yang sangat menentukan dalam pembentukan karakter dan kepribadian. Dalam UU RI No 20 tahun 2003 juga ditegaskan bahwa yang termasuk dalam anak usia dini adalah anak dengan rentang usia 0-6 tahun. Usia dini merupakan usia yang sangat penting bagi perkembangan anak sehingga disebut golden age. Perkembangan ini demikian pentingnya sehingga mendapat perhatian yang cukup luas dari para pakar psikologi/pendidikan, yang menyatakan bahwa pendidikan untuk anak usia dini harus disesuaikan dengan pertumbuhan dan perkembangan anak. Prinsip tersebut dinamakan praktek-praktek yang sesuai dengan perkembangan anak developmentally appropriate practice (Bredekamp, 1987).

Toleransi adalah kemampuan untuk hidup secara harmoni dengan orang lain(Ladlia, 2010), sebagai pilihan yang disengaja untuk tidak mengganggu perilaku yang tidak disetujui (Burwoth \& Weith, 1998), yang meliputi kebiasaan bersabar, tenggang rasa, serta menahan emosi dan keinginan (Kemendikbud, 2012). Makna “toleran” menunjukan bahwa jika seseorang ingin mengembangkan toleransinya untuk mencapai level moralitas.

Penelitian Glover (dalamAbdullah, 2009); Palmer, 1990; Ramsey \& Myers 1990, menemukan bahwa anak usia dini sudah dapat memberitahukan tiga perbedaan seperti kulit, mata dan warna rambut. Anak usia dini mulai mengembangkan identitas diri dan membandingkannya dengan orang lain. Pada usia 5 tahun anak sudah dapat memahami tentang budaya (Linch \& Hanson, dalamAbdulah, 2009). Guru di TK dapat membantu anak untuk menyadari keanekaragaman dan perbedaan 
budaya, sehingga anak dapat menghargai perbedaan ketika berada di lingkungan yang memiliki bermacam-macam budaya (Davidman \& Davidman, dalam Tarman \& Tarman, 2011).

Lickona (2002) mengatakan bahwa toleransi memiliki dua nilai dasar sebagai aspek, yaitu respect dan appreciation of diversity. Respect, adalah nilai kebaikan yang mendorong anak bersikap baik dan menghormati orang lain (Borba, 2001). Appreciation of diversity adalah memandang bahwa setiap orang dengan berbagai latar belakang suku, agama, negara dan agama memiliki kontribusi dan kualitas positif. Pada periode usia dini, anak mulai mempelajari cerita tentang diri mereka dan teman sebaya. Misalnya penampilan fisik, nama, hari yang penting, tempat yang penting, makanan favorit, bahasa yang mereka gunakan, dan keunikan pakaian yang digunakan sehingga anak akan menerima dan mengapresiasi perbedaan nilai antara mereka dan teman sebaya (Ladlia, 2010).

Sekolah sebagai tempat yang mewakili komunitas masyarakat merupakan cermin keragaman dalam masyarakat, karena itu sekolah dapat membantu anak memahami dan menghormati keragaman. Sekolah dapat mengajarkan nilai-nilai demokratis yang meliputi menghargai perbedaan agama, suku, budaya dan orientasi seksual (Blum, 2010). Kuncinya adalah dengan membangun pemahaman anak-anak tentang perbedaan budaya, menghargai perbedaan,

dan pada saat yang sama, mengatasi hambatan rasial dan etnis (Pattnaik, 2003).

Hurlock (2010) menyebutkan bahwa memahami sama dengan mengerti. Pengertian dicapai dengan menerapkan pengetahuan yang didapat sebelumnya dengan pengalaman dan situasi baru. Pengetahuan adalah proses belajar manusia mengenai kebenaran atau jalan yang benar, secara mudahnya mengetahui apa yang harus diketahui untuk dilakukan (Nadler, 1986).

Guru dapat menggunakan pengetahuan siswa tentang pelajaran multikultural seperti budaya dan etnis sebagai kerangka kerja untuk melakukan inquiry serta melaksanakan instruksi (Benks et. all, dalam Tarman \& Tarman 2011). Teori belajar konstruktivisme mendukung model inquiry atau penyelidikan ini dengan fokus belajar pada ide, pertanyaan, dan pengetahuan anak, bukan pada guru (Eick \& Redd, 2002). Menurut teori konstruktivisme semua pengetahuan yang dibangun oleh siswa adalah dengan menggunakan pengalaman masa lalu dan struktur pengetahuan yang sudah ada (Paksu \& Ubud, 2009).

Definisi belajar menurut konstruktivisme adalah aktivitas yang aktif, dimana peserta didik membina sendiri pengetahuannya, mencari arti dari apa yang mereka pelajari dan merupakan proses menyelesaikan konsep dan ide-ide baru dengan kerangka berfikir yang telah ada dan dimilikinya sehingga pengetahuannya dapat dikembangkan (Shymansky \& Keylle, 1992).

Guru dalam kelas dengan model inquiry membantu dan membimbing siswa menghasilkan konten yang berhubungan dengan pertanyaan, hal ini bertujuan untuk memberikan pengalaman, membangun pemahaman baru, menumbuhkan rasa ingin tahu siswa sehingga memunculkan keinginan anak untuk menemukan solusi dari permasalahan atau produk akhir (Branch \& Oberg, 2004).

Pengembangan karakter dilakukan dengan menanamkan nilai-nilai etika dasar sebagai basis bagi karakter yang baik. Tujuannya adalah agar anak mempunyai karakter yang baik (Borba, 2001). Bentuk program pembelajaran yang digunakan dalam memperkenalkan nilai-nilai pada siswa antara lain adalah dengan memberikan pengalaman secara langsung (Gruener, Stott \& Jackson, dalam Lewis, 2011). Pengalaman secara langsung dapat diperoleh melalui bermain peran (Laird \& House dalam Flanning, 2011; Wook \& Cook, 2009).

Bermain peran adalah praktik kelompok yang melibatkan fisik dan berpura-pura (Simsarian, 2003). Bermain peran yaitu berpurapura menjadi orang lain sebagai cara belajar 
keterampilan baru atau pemahaman. Melalui bermain peran, informasi yang relevan dengan pengalaman pribadi peserta didik yang berakting akan melibatkan emosi, yang selanjutnya berkontribusi mengubah persepsi dan juga perilaku (Taylor, Diamini, Khanyile \& Mpanza, 2012). Ketika bermain peran akan terjadi proses belajar kognitif, afektif dan perilaku yang nantinya akan membentuk suatu pengalaman (Kolb, Boyatzis, \& Maenemelis, 2001). Dengan bermain peran, anak terlibat secara aktif, sehingga secara signifikan bermain peran menghindarkan anak dari lingkungan kelas yang membosankan dan menuntut anak untuk berperilaku sesuai aturan di kelas, sehingga anak mendapat kebebasan dalam memperoleh pengalaman langsung (Laird dan House dalam Fanning, 2011; Wood dan Cook, 2009).

Penelitian ini dilakukan di dua sekolah Taman Kanak-Kanak, di mana pada satu sekolah akan diberikan intervensi bermain peran "pelangi di sekolahku” dan di sekolah lain tidak. Tujuan dari penelitian ini adalah untuk melakukan validasi modul bermain peran "pelangi di sekolahku" terhadap pengetahuan toleransi pada anak usia dini khususnya siswa di TK.

Hipotesis yang diajukan yaitu modul bermain peran "pelangi di sekolahku" dapat meningkatkan pengetahuan toleransi pada siswa di TK. Ada perbedaan tingkat pengetahuan anak usia dini (TK) yang mendapat perlakuan berupa modul bermain peran "pelangi di sekolahku" (kelompok eksperimen) dengan yang tidak mendapat perlakuan (kelompok kontrol).

\section{METODE PENELITIAN}

Variabel tergantung dalam penelitian ini adalah pengetahuan toleransi, yaitu proses belajar mengetahui apa yang harus dilakukan untuk hidup secara harmoni dengan orang lain. Untuk dapat hidup harmoni dengan orang lain, individu memiliki pilihan untuk tidak menganggu perilaku yang tidak disetujui yang ditunjukan dengan perilaku bersabar, memiliki tenggang rasa, serta menahan emosi dan keinginan. Variabel bebas adalah bermain peran, yaitu praktik kelompok yang melibatkan fisik dan berpura-pura. Bermain peran yaitu berpura-pura menjadi orang lain sebagai cara belajar keterampilan baru atau pemahaman. Ketika bermain peran akan terjadi proses belajar kognitif, afektif dan perilaku yang nantinya akan membentuk suatu pengalaman.

Partisipan dalam penelitian ini adalah:

a. Anak usia 5-6 tahun yang duduk di kelas TK B. Pada usia tersebut anak mampu terlibat dengan banyak teman dalam permainan yang mengandung kerja sama, pararel, mematuhi aturan, memahami sopan santun, memecahkan masalah dan membuat prediksi dengan mengobservasi, serta menghubungkan sesuatu dengan pengalaman (Dodge, et, al, 2003). Selain itu, anak usia 5-6 tahun menunjukkan lebih banyak kemampuan sosial. Hal ini dapat dilihat dari cara bermain anak yang lebih terarah dan mampu bekerja sama dalam bermain. Anak senang bermain bersama dan tolong menolong dalam mencapai keinginan tertentu. Ada kecenderungan tolong menolong ini dalam bermain dan kegiatan lainya. Anak sudah mampu berbagi dengan orang lain, mampu bertenggang rasa, sabar menunggu gilirannya dan mampu menerima tanggung jawab yang ringan (Stenberg, 1985).

b. Mengikuti pendidikan di Taman KanakKanak (TK) atau yang sederajat, serta berasal dari TK homogen (tidak ada perbedaan agama) dan TK yang heterogen (terdapat perbedaan agama).

c. Berasal dari sekolah atau TK yang gurunya sudah mengikuti pelatihan menyusun program pembelajaran pendidikan karakter pada anak usia dini.

Pada penelitian ini, alat ukur yang digunakan adalah : 
1. Alat ukur pengetahuan toleransi untuk anak usia prasekolah.

Alat untuk mengukur pengetahuan toleransi dibuat dalam bentuk gambar yang terdiri dari gambar yang dibuat berdasarkan aspek-aspek toleransi yang dikemukakan Lickona (2002). Instrumen berupa situasi dalam kehidupan (life setting) sehari-hari anak usia prasekolah dan ada keterlibatan dengan teman sebaya. Objek dalam gambar merupakan bagian dan situasi (tidak terlalu banyak gambar, sehingga tidak memecah perhatian anak dalam memahami situasi.

2. Modul Pengajaran Metode Bermain Peran Perlakuan yang diberikan dalam penelitian ini adalah pengajaran dengan metode bermain peran. Modul pengajaran dirancang bagi anak-anak usia prasekolah dengan tujuan memberikan pengetahuan tentang toleransi. Modul tersebut berisi landasan konsep bermain peran, rangkaian prosedur atau tahapan dalam bermain peran, dan setting atau dilema masalah yang akan diperankan oleh anak. Dalam situasi masalah anak akan dihadapkan pada situasi yang mengharapkan mereka memperlakukan orang lain dengan baik, hormat dan menghargai perbedaan antara dirinya dengan orang lain.

Penelitian yang dilakukan menggunakan metode eksperimen kuasi. Rancangan yang dipilih adalah untreated control group design with pretest and posttest, dimana di dalamnya terdapat dua kelompok yaitu kelompok kontrol (kelompok yang tidak memperoleh perlakuan) dan kelompok eksperimen (kelompok yang mendapat perlakuan). Rancangan tersebut dipilih dengan pertimbangan merupakan salah satu rancangan yang paling dapat diinterpretasikan dalam penelitian sosial (Shadish, Cook, dan Campbell, 2002).

Validitas dan Reliabilitas Alat Ukur Pengetahuan Toleransi Untuk Anak menggunakan validitas content. Validitas content yang digunakan menggunakan model validasi isi formula Aiken's V (Azwar, 2012). Para Ahli melakukan penilaian dengan cara memberikan angka antara satu (yaitu sangat tidak mewakili atau sangat tidak relevan dengan (indikator keperilakuannya) sampai dengan lima (yaitu sangat mewakili atau relevan dengan indikator keperilakuannya), jika memberikan penilaian kurang dari lima, maka diharapkan para expert judgement memberikan masukan, usul ataupun saran. Beberapa usul atau koreksi dijadikan pertimbangan untuk memperbaiki instrument alat ukur pengetahuan toleransi.

Instrumen alat ukur ini selanjutnya diujicobakan kepada 30 anak yang memiliki karakteristik sama dengan subjek penelitian. Indeks daya beda yang diperoleh adalah antara 0,272- 0,600. Daya beda yang digunakan dalam skala ini adalah e" 0,30, karena menurut Azwar (2003), aitem yang memiliki koefisien korelasi minimal 0,30 daya bedanya dianggap memuaskan. Item yang memiliki koefisien korelasi kurang dari 0,30 dianggap gugur. Dalam penelitian ini, item yang gugur adalah item nomor 6. Hasil uji coba skala pengetahuan toleransi pada anak usia prasekolah menunjukan koefisien reliabilitas sebesar 0,733 .

\section{Modul Bermain Peran "Pelangi Di Sekolahku"}

Modul yang digunakan dalam penelitian ini adalah modul bermain peran "Pelangi Di Sekolahku” yang disusun peneliti berdasarkan aspek toleransi yang dikemukakan oleh Lickona (2002) yaitu respect dan appreciation of diversity. Penyusunan isi modul mengacu pada teori konstruktivisme, yaitu siswa terlibat aktif untuk mendapatkan pengetahuan dan guru sebagai pembimbing.

Modul divalidasi dengan model pendekatan isi, yaitu validitas yang diestimasi melalui pengujian terhadap isi dengan analisis 
rasional dan penilaian dari individu yang dianggap ahli di bidangnya. Pada penelitian ini ahli yang diminta melakukan penilaian adalah dua orang guru TK sebagai praktisi pendidikan yang terlibat langsung dalam dunia pendidikan anak usia dini dan psikolog yang memiliki minat, kompetensi dan pengalaman dalam penelitian anak usia dini.

Peneliti meminta para ahli untuk memberi penilaian kesesuaian antara isi materi modul dengan teori. Penilaian yang digunakan mengacu pada model validasi isi formula Aiken's V (Azwar, 2012). Para Ahli melakukan penilaian dengan cara memberikan angka antara satu (yaitu sangat tidak mewakili atau sangat tidak relevan dengan teori ) sampai dengan lima (yaitu sangat mewakili atau relevan dengan teori).

Dari hasil uji coba tersebut diperoleh waktu yang dibutuhkan untuk bermain peran paling lama adalah 30 menit. Selain itu, ada perubahan pada kata pengantar oleh guru, yang disesuaikan dengan pemahaman anak usia dini. Untuk alat dan media yang digunakan dalam bermain peran dibuat menarik sesuai dengan keadaan yang sebenarnya untuk membuat anak bersemangat dan senang pada waktu melakukan bermain peran.

Metode statistik yang digunakan untuk menguji hipotesis menggunakan anova mixed design. Dinamakan Mixed Design (campuran) karena di dalamnya memadukan dua sub analisis yaitu Within Subject Test dan Between Subject Test. Within Subject Test adalah pengujian perbedaan skor dalam satu kelompok (pre vs pos) dan Between Subject Test adalah pengujian perbedaan skor antar kelompok (eksperimen vs kontrol) (Widhiarso, 2011). Analisis data akan dilakukan dengan menggunakan program SPSS (Statistical Product and Service Solution) versi 15.0

\section{HASIL DAN PEMBAHASAN}

Uji normalitas dilakukan dengan teknik Kolmogorov-Smirno. Hasilnya menunjukan nilai sig pretest 0,818 dan posttes $0,306,(\mathrm{p}>0,05)$ yang artinya sebaran data normal. Hasil uji homogenitas dari skor pengetahuan toleransi pada kelompok kontrol dan kelompok eksperimen menunjukan nilai sig 0,212, $(\mathrm{p}>0,05)$ menunjukan data homogen.

Uji hipotesis pada penelitian yang menggunakan Anava Mixed. menunjukan bahwa $\mathrm{F}=29,898,(\mathrm{p}<0,01)$ artinya bahwa tedapat interaksi antara waktu (pretest dan postets) dan group (eksperimen dan kontrol). Interaksi menunjukan bahwa perubahan skor pretest menuju posttest pada kedua kelompok (eksperimen dan kontrol) terdapat perbedaan signifikan.

Hasil analisis data ini memberikan arti bahwa hipotesis penelitian yang berbunyi modul bermain peran "pelangi di sekolahku” dapat meningkatkan pengetahuan toleransi pada siswa di TK diterima. Secara lebih detail perubahan skor pengetahuan toleransi adalah pada tabel pairwise comparisons di bawah ini.

Tabel 1 . Interaksi masing-masing waktu Pairwise Comparisons

\begin{tabular}{lllll}
\hline Grup & (I) time & $(\mathbf{J})$ time & MD (I-J) & Sig \\
\hline 1 (Kontrol) & 1 & 2 & $-0,556$ & 0,402 \\
& & 3 & $-1,000$ & 0,142 \\
2 (Eksperimen) & 1 & 2 & $-7,85$ & 0,000 \\
& & 3 & $-5,500$ & 0,000 \\
\hline
\end{tabular}

Tabel pairwise menunjukan bahwa ada perubahan pengetahuan toleransi pada kelompok eksperimen adalah signifikan (MeanDifference $=-7,85 ; \mathrm{p}<0,01)$, sedangkan perubahan pengetahuan toleransi pada kelompok kontrol tidak siginifikan $(\mathrm{MD}=-0.556 ; \mathrm{p}>0,05)$. Hal ini menunjukan bahwa program bermain peran “Pelangi Di Sekolahku” dapat meningkatkan pengetahuan toleransi pada kelompok eksperimen. Hasil partial eta square pada kelompok eksperimen diketahui sebesar 0,791, 
hal ini menunjukan bahwa sumbangan efektif pelatihan pada kelompok eksperimen adalah sebesar $79,1 \%$.

Penelitian ini bertujuan mengetahui modul bermain peran "pelangi di sekolahku” terhadap pengetahuan toleransi anak usia dini khususnya siswa di TK. Berdasarkan analisis data dengan anava campuran diperoleh (MD $=-7,85$ $(p<0,01)$. Hasil tersebut menunjukan adanya perubahan skor yang signifikan, maka dapat disimpulkan bahwa modul bermain peran "pelangi di sekolahku” dapat meningkatkan pengetahuan toleransi pada anak usia TK.

Hasil yang diperoleh dalam penelitian ini sesuai dengan pendapat Borba (2001) bahwa agar anak mempunyai karakter yang baik, perlu ditanamkan nilai-nilai etika sebagai basis karakter yang baik. Sekolah dapat mengajarkan nilai-nilai demokratis yang meliputi menghargai perbedaan agama, suku, budaya dan orientasi seksual (Blum, 2010). Kuncinya adalah dengan membangun pemahaman anak-anak tentang perbedaan budaya, menghargai perbedaan,

dan pada saat yang sama, mengatasi hambatan rasial dan etnis (Pattnaik, 2003). Hurlock (2010) menyebutkan bahwa mengerti sama dengan kemampuan memahami. Pengertian dicapai dengan menerapkan pengetahuan yang didapat sebelumnya dengan pengalaman dan situasi baru. Pengetahuan adalah proses belajar manusia mengenai kebenaran atau jalan yang benar, secara mudahnya mengetahui apa yang harus diketahui untuk dilakukan (Nadler, 1986).

Membentuk karakter toleransi sebaiknya dilakukan sejak usia dini. Anak diperkenalkan dengan nilai-nilai toleransi agar anak mengetahui bahwa untuk dapat hidup secara damai dan harmonis dengan orang lain diperlukan perilaku bersabar, memiliki tenggang rasa, menahan emosi dan keinginan. Bentuk program pembelajaran yang digunakan dalam memperkenalkan nilai-nilai pada siswa antara lain adalah dengan memberikan pengalaman secara langsung (Gruener, 2006; Stott \& Jackson, 2009; dalam
Lewis, 2011). Pengalaman secara langsung dapat diperoleh melalui bermain peran (Laird \& House dalam Flanning, 2011; Wook \& Cook, 2009).

Bermain peran adalah praktik kelompok yang melibatkan fisik dan berpura-pura (Simsarian, 2003). Bermain peran yaitu berpurapura menjadi orang lain sebagai cara belajar keterampilan baru atau pemahaman. Melalui bermain peran, informasi yang relevan dengan pengalaman pribadi peserta didik yang berakting akan melibatkan emosi, yang selanjutnya berkontribusi mengubah persepsi dan juga perilaku (Taylor, Diamini, Khanyile \& Mpanza, 2012). Bermain peran sebagai strategi mengajar menawarkan tiga keuntungan untuk guru dan murid (Jarvis, Odell dan Triano, 2002). Adapun keuntungan yang didapat adalah sebagai berikut: meningkatkan minat siswa dalam pada topik yang dibahas, terjadi peningkatan keterlibatan siswa dimana siswa tidak pasif namun terlibat aktif dalam proses mendapat pengetahuan serta mengajarkan empati dan pemahaman dari perspektif yang berbeda. Sesuai dengan pendapat tersebut, pada saat bermain peran dilakukan anak mengikuti setiap sesi yang dimainkan dengan senang dan antusias.

Proses belajar dimana siswa terlibat aktif dalam memperoleh pengetahuan sesuai dengan teori konstruktivisme. Definisi belajar menurut konstruktivisme adalah aktivitas yang aktif, dimana peserta didik membina sendiri pengetahuannya, mencari arti dari apa yang mereka pelajari dan merupakan proses menyelesaikan konsep dan ide-ide baru dengan kerangka berpikir yang telah ada dan dimilikinya sehingga pengetahuannya dapat dikembangkan.

Pelaksanaan bermain peran dilaksanakan di TK yang homogen secara agama dengan pertimbangan anak tidak menemui adanya perbedaan. Adapun jadwal pelaksanaan disepakati pada hari selasa, rabu, kamis dan sabtu. Bermain peran dimulai pada pukul 08.00 WIB, setelah kegiatan pembuka. Alasan dilaksanakan pagi hari karena anak masih segar 
dan bersemangat dalam melakukan aktivitas. Dalam penelitian ini, setiap sesi bermain peran dilaksanakan sesuai isi modul. Setiap sesi diikuti anak dengan bersemangat. Rata-rata anak berperan aktif dengan mengajukan diri sebagai pemeran ketika diminta oleh guru untuk maju kedepan. Anak tertarik untuk ikut bermain peran karena media yang digunakan menarik untuk anak. Pada penelitian ini media yang dipakai antara lain adalah rambut palsu, terompet serta permainan yang biasa dimainkan oleh anak seperti balok dan plastisin.

Untuk membantu anak dalam mencari pengetahuannya, guru berperan sebagai pendamping yang mendukung anak untuk berkembang sesuai dengan kemampuannya. Peran guru dalam bermain peran adalah memberikan informasi dengan memberikan pertanyaan agar muncul berbagai kemungkinan jawaban dari anak. Pertanyaan dibuat sesuai dengan tema bermain peran yang akan diperankan dan disesuaikan dengan pemahaman anak usia dini.

Kegiatan bermain peran berlangsung relatif lancar sesuai dengan jadwal yang telah dibuat. Pada pelaksanaannya, dari 22 orang siswa pada kelompok eksperimen hanya 14 orang anak yang mengikuti seluruh sesi bermain peran. Sedangkan untuk kelompok kontrol dari 26 orang anak yang mengikuti seluruh kegiatan pengukuran pengetahuan toleransi adalah 18 orang anak. Salah satu faktor yang mendukung berhasilnya metode bermain peran dalam meningkatkan pengetahuan toleransi pada anak usia prasekolah adalah guru yang sudah memiliki pengalaman berinteraksi dengan anak dan merupakan figur yang familiar dengan anak sehingga anak tidak merasa canggung atau takut ketika bermain peran.

Lokasi penelitian berpengaruh terhadap pembuatan alat ukur. Pada penelitian ini dipilih karakter berkulit hitam dan berambut keriting yang jarang ditemui atau dilihat oleh anak di lokasi penelitian. Pada alat ukur dengan gambar rumah ibadah dipilih yang secara umum mudah ditemui dan biasa dilihat anak di lokasi penelitian. Selanjutnya alat ukur gambar yang dibuat merupakan keseharian anak di sekolah secara umum.

\section{SIMPULAN}

Modul bermain peran "pelangi di sekolahku" dapat meningkatkan pengetahuan toleransi pada anak usia prasekolah khususnya pada anak TK dan dapat digunakan sebagai salah satu cara untuk mengajarkan anak menghormati orang lain dan menghargai perbedaan. Saran bagi peneliti selanjutnya yang ingin melakukan penelitian dengan tema yang sama adalah: Mencari definisi toleransi yang sesuai dengan budaya Indonesia dengan menggali lebih dalam makna toleransi dari berbagai sudut pandang individu, dan modul bermain peran pelangi di sekolahku perlu diujikan lagi pada anak TK yang memiliki murid heterogen dalam hal agama. Adapun keterbatasan dalam penelitian ini adalah : (1) definisi toleransi yang digunakan dalam penelitian ini belum disesuaikan dengan budaya Indonesia sehingga diperlukan untuk menggali definisi toleransi dari berbagai sudut pandang individu, (2) alat ukur dan modul yang digunakan tidak bebas budaya, sehingga harus disesuaikan dengan karakterisitik daerah yang dijadikan tempat penelitian.

\section{DAFTAR PUSTAKA}

Abdullah, C.A. (2009). Multicultural Education in Early Childhood: Issues and Challenges. CICE Hiroshima University, Journal of International Cooperation in Education, 12(1), 159-175.

Aboud, F. E., \& Doyle, A. B.(1996). Does talk of race foster prejudice or tolerance in children?. Canadian Journal of 
Behavioural Science, 28, 161-170.

Azwar, S. (2012a). Penyusunan Skala Psikologi. Yogyakarta: Pustaka Pelajar.

Azwar, S. (2012b). Validitas dan Reliabilitas. Yogyakarta: Pustaka Pelajar.

Bergen V. C. W., Collier, G. (2009). Moving From Tolerance As Acceptance To Tolerance As Civillity In Contemporary Workplace Diversity Initiatives. Department of Management \& Marketing 211 Russell Building 1405 N. 4th Avenue, PMB 4103 Durant, Oklahoma 74701-0609. Southeastern Oklahoma State University.

Blum, L. (2010). Secularism, multiculuturalism, and same-sex marriage: a common on Brenda Almond's Education for tolerance. Journal of Moral Education. 39(2), 145-150.

Borba, M. (2001). Building Moral Intelligence : The Seven Essential Virtues That Teach Kids to Do The Right Thing. Jossey - Bass.

Branch, J., Oberg, D. (2004). Focus on Inqury: A Teacher's Guide To Implementing Inquiry-Based Learning. Canada:Alberta Learning. http.www.learning.gov.ab.ca. Diunduh 12 Januari 2013.

Brederkamp. (1987). Developmentaly Appropriate Pratice In Early Childhood Program Serving Children from Birth to Age 8. Washington DC. NAEYC.

Dogde, D. T., Colker, L.J., Heroman, C. (2003). Creative Curriculum for Preshcool. Washington, DC : Teaching Startegis. Inc.
Eick, J. C., \& Redd, J. A. (2001). What Makes an Inquiry-Oriented Science Teacher? The Influence of Learning Histories on Student Teacher Role Identity and Practice. Science teacher education, 86, 401-416.

Flanning, F. E (2011). Enganging Learners, Techniques to Make Training Stick. Profesional Safety. http:// www.asse.org. Diunduh 20 Desember 2012.

Hurlock, E. (2010). Perkembangan Anak.

jilid 1. Jakarta : Penerbit Erlangga.

JJPN. (2010). Indonesia Memiliki 1.128 Suku Bangsa. Diunduh dari http:// w w w j j $\mathrm{n} \mathrm{n}$. c o m / index.php?mib=berita.detail\&id=57455

Kementrian Pendidikan dan Budaya. (2012). Pedoman Pendidikan Karakter bagi AUD. Direktorat Jenderal Pendidikan Anak Usia Dini, Nonformal dan Informal. Direktorat Jenderal Pendidikan AUD.

Kolb, D. A., Boyatzis, R. E., \& Mainemelis, C. (2001). Experiential Learning Theory: Previous research and new direction. Perspective of thinking. Learning and cognitive style. 33(1). 5-33.

Ladlia, K. (2010). Tolerance of Early Childhood Children in Multicultural Group in Yala Province, Thailand:ADevelopment of Literature-Based Teaching Model. International Journal for CrossDisciplinary Subjects in Education (IJCDSE), 1(4), 201-207.

Lewis. V. Sallly., Robinson. H. E., \& Hayes, G. (2011). Implementing an Authentic Character Education Curriculum. 
ChildhoodEducation. 87(4), 227-231

Lickona, T. (2002). Making Sense of Tolerance and Diversity. The Fourth and Fifth Rs. 8(2), 1-3.

Nadler, G. (1995). Terobosan Cara Berpikir. Penerbit: Abdi Tandur.

Paksu, A.D. , \& Ubuz, B. (2009) . Effects of Drama-Based Geometry Instruction on Student Achievement, Attitudes, and Thinking Levels. The Journal of Educational Researh. 102 (4). 272286.

Palmer, G. (1990). Presschool children and race: an Australian study. Australian Journal of Early Childhood, 15(2), (3-8).

Pattnaik, J. (2003). Learning about the other: Building a case for intercultural understanding among minority children. Childhood Education, 79(4), 204211.

Shadis, W. R., Cook, T.D., Campbell, D.T. (2002). Experimental and Quasi experimental design for generalized causal inference. Boston: Houghton Mifflin Company.

Shaftel, F. R., \& Shaftel, G. (1982). Role Playing in the Curriculum. New Jersey : Prentice Hall.

Shymansky, J. A., \& Keyle, W.C. 1992. Establishing a research agenda: critical issues of science curriculum reform. JRST. 30(7) 745-747.

Simsaria, K. (2003). Take It to the next stage : The roles of role playing in the design process. IDEO-San Francisco.

Soekanto, S. 1990. Sosiologi Suatu Pengantar.
Jakarta : Rajawali Pers.

Sternberg, R. J. (1985): Beyond IQ: A triarchic theory of human intelligence. New York: Cambridge University Press.

Sujino. S. (2009). Konsep Dasar Pendidikan Anak Usia Dini. Jakarta. Departemen Pendidikan Nasional Direktorat Jendral Pendidikan Tinggi Direktorat Pembinaan Pendidikan Tenaga Kerja Kependidikan dan Ketenagakerjaan Perguruan Tinggi.

Tarman, I., \& Tarman, B. (2011). Developing Effective Multikultural Practices : A Case Study Of Exploring A Teacher's Understand And Practices. The Journal of International Social Research .4(17), 579-598.

Taylor, M., Diamini, N., Khanyile, Z., \& Mpanza, L. ( 2012). Exploring the use of role play in a school-based programme to reduce teenage pregnancy. South African Journal of Education. 32(4), 442-448.

Vandenbrock, M. (2011). Diversity in Early Childhood Services. Encyclopedia on Early Childhood Development. Diunduh dari: $\underline{\text { http://www.child. }}$ encyclopedia.com/documents/ VandenbroeckANGxp1.pdf

Witenberg, R. (2000). Do Unto Others: Toward Understanding Racial Tolerance and Acceptance. Journal of College and Character. 1(5). 1940-1639.

Wood, E., Cook, J. (2009). Gendered discourses and practices in role play activities: A Case Study of Young Children in the English Foundation Stage. Educational \& Child Psychology. 26 (2). 1930. 